\title{
Alterations in the Establishment and Maintenance of Epithelial Cell Polarity as a Basis for Disease Processes
}

\author{
Bruce A. Molitoris* and W. James Nelson* \\ ${ }^{*}$ Department of Medicine, Veterans Administration Medical Center, University of Colorado School of Medicine, Denver, \\ Colorado 80220; and ${ }^{\ddagger}$ Institute for Cancer Research, Fox Chase Cancer Center, Philadelphia, Pennsylvania 19111
}

Polarized epithelial cells play fundamental roles in the vectorial movement of ions, water, and macromolecules between biological compartments. These vectorial processes include absorption (enterocytes and renal proximal tubule cells), secretion (hepatocytes, endocrine and exocrine cells), and exchange (alveolar cells and capillary endothelium). The ability to conduct these vectorial processes is dependent on the structural and functional organization of epithelial cells into: $(a)$ structurally, biochemically, and physiologically distinct apical and basolateral plasma membrane domains that contain different ion channels, transport proteins, enzymes, and lipids; and $(b)$ cell-cell junctional complexes that integrate cells into a monolayer forming a cellular barrier between biological compartments.

The establishment and maintenance of this specialized cellular organization is a multistage process involving the formation of cell-cell and cell-substratum contacts, and the establishment and maintenance of the polarized distributions of plasma membrane and cytoplasmic components. Aberrations in any stage of this process could result in the development of cell- and tissue-specific abnormalities, and ultimately a pathologic state.

In this review we describe recent findings regarding basic cellular mechanisms involved in the organization of polarized epithelial cells. These fundamental cellular concepts are then used as a foundation for discussing potential alterations involved in disease processes in epithelial cells.

\section{Characteristics of polarized epithelial cells}

Distinct surface membrane domains. Polarized epithelial cells have a characteristic cellular organization that includes a surface plasma membrane organized into distinct apical and basolateral domains. Within these surface membrane domains enzymes, transport proteins, hormone receptors, and lipids are localized in a polarized fashion (Table I; for review, see references 1 and 2). Apical membranes face the external compartment and are composed of membrane proteins with specialized properties related to the cell's primary function (e.g., absorption). The basolateral membrane domain faces the

Address correspondence to Dr. Bruce A. Molitoris, Department of Medicine (111C), V.A. Medical Center, 1055 Clermont St., Denver, CO 80220.

Received for publication 11 October 1989 and in revised form 16 October 1989.

J. Clin. Invest.

(C) The American Society for Clinical Investigation, Inc.

$0021-9738 / 90 / 01 / 0003 / 07 \$ 2.00$

Volume 85, January 1990, 3-9 internal milieu and has a compliment of intrinsic and extrinsic membrane proteins found over the entire surface membrane of nonpolarized cells. These basolateral membrane proteins maintain the normal physiologic state of the cell and also participate in signal recognition and transduction. The lipid composition of apical and basolateral membranes also differs markedly (Table I; for review, see reference 3). This difference is responsible for large physiochemical differences between the two membrane domains (4) and influences the function of numerous membrane proteins. The establishment and maintenance of these specific apical and basolateral membrane protein and lipid differences is essential for the efficient functioning of polarized epithelial cells. For example, sodium reabsorption by renal proximal tubular cells is dependent on the polarized localization of specific carrier proteins such as the $\mathrm{Na}^{+} / \mathrm{H}^{+}$antiporter and glucose, amino acid- and phosphate $\mathrm{Na}^{+}$-dependent cotransporters to the apical membrane, and the polarized distribution of $\mathrm{Na}^{+}, \mathrm{K}^{+}$-ATPase to the basolateral membrane.

Junctional complex. The lateral membrane domain possesses a specialized intercellular junctional complex composed of zonula occludens (tight junction), zonula adherens (intermediate junction), desmosomes, gap junctions, and cell adhesion proteins (Fig. 1). The components of the junctional complex have four important functions: (a) regulating initial cellcell recognition and adhesion (cell adhesion proteins); $(b)$ maintaining the cohesive structural integrity of the epithelial monolayer (intermediate junctions and desmosomes); (c) allowing for intercellular communication (gap junctions); and (d) (the tight junction) regulating the permeability of the paracellular pathway ("gate" function) and maintaining the protein and lipid differences between apical and basolateral membrane domains ("fence" function) $(5,6)$.

The basal membrane contains specialized proteins that regulate cell-substratum interactions. Cell attachment to the substratum occurs via specific receptors to type IV collagen, proteoglycan, and laminin $(7,8)$, is tissue specific, and is important for epithelial morphogenesis, maintenance of the differentiated state, and tissue-specific gene expression $(7,8)$.

Cytoskeletal organization. The structural organization of epithelial cells is dependent on the polarized nature of the cytoskeleton and its interaction with the surface membrane (Fig. 1; 9-11). Actin microfilaments and their associated proteins interact with surface membrane proteins via direct or indirect linkages to fodrin (termed spectrin in erythrocytes), ankyrin, protein 4.1 , vinculin, the $110-\mathrm{kD}$ protein (brush border myosin I) of the microvillus, and talin (11). For example, ankyrin binds with high affinity to $\mathrm{Na}^{+}, \mathrm{K}^{+}$-ATPase (12), and a complex containing $\mathrm{Na}^{+}, \mathrm{K}^{+}$-ATPase, ankyrin, and fodrin has been detected in extracts of Madin-Darby canine kid- 
Table I. Asymmetry of the Surface Membrane of Polarized Epithelial Cells

\begin{tabular}{|c|c|c|}
\hline Characteristic & Apical membrane & $\begin{array}{l}\text { Basolateral } \\
\text { membrane }\end{array}$ \\
\hline \multicolumn{3}{|l|}{ Proteins } \\
\hline Enzymes & $\begin{array}{l}\text { Leucine aminopeptidase } \\
\text { Maltase } \\
\text { GPI-linked proteins } \\
\text { (alkaline phosphatase) }\end{array}$ & Adenylate cyclase \\
\hline Receptors & & $\begin{array}{l}\text { Insulin } \\
\text { Parathyroid } \\
\text { hormone } \\
\text { Epidermal } \\
\text { growth factor } \\
\text { Laminin }\end{array}$ \\
\hline ATPases & $\begin{array}{l}\mathrm{H}^{+} \text {-ATPase } \\
\mathrm{Mg}^{2+} \text {-ATPase }\end{array}$ & $\begin{array}{l}\mathrm{Na}^{+}, \mathrm{K}^{+} \text {-ATPase } \\
\mathrm{Ca}^{2+} \text {-ATPase }\end{array}$ \\
\hline Carriers & $\begin{array}{l}\text { Amiloride-sensitive } \mathrm{Na}^{+} \\
\text {channel } \\
\mathrm{Na}^{+} \text {-dependent } \\
\text { cotransporters } \\
\mathrm{Na}^{+} / \mathrm{K}^{+} / \mathrm{Cl}^{-} \\
\text {cotransporter } \\
\mathrm{Na}^{+} / \mathrm{H}^{+} \text {antiporter }\end{array}$ & $\begin{array}{l}\mathrm{Cl}^{-} / \mathrm{HCO}_{3} \\
\text { exchanger } \\
\mathrm{Na}^{+} \text {-independent } \\
\text { glucose carrier }\end{array}$ \\
\hline \multicolumn{3}{|l|}{ Lipids } \\
\hline Cholesterol & High & Low \\
\hline Sphingomyelin & High & Low \\
\hline Phosphatidylcholine & Low & High \\
\hline Phosphatidylinositol & Low & High \\
\hline \multicolumn{3}{|l|}{ Physical properties } \\
\hline Electrical resistance & High & Low \\
\hline Membrane fluidity & Low & High \\
\hline
\end{tabular}

ney (MDCK) $)^{1}$ epithelial cells (13), demonstrating a direct linkage of cytoskeletal proteins to a specific integral membrane protein. Cytokeratin intermediate filaments, composed of bundles of protein filaments, attach to the surface membrane at maculae adherens (desmosomes) and hemidesmosomes, and provide a structural continuum between adjacent cells and with the substratum (11). Microtubules are aligned with the apico-basal axis of the cell, and they determine the spatial orientation of the endoplasmic reticulum, Golgi apparatus, and lysosomes $(14,15)$, and the distribution of actin microfilaments within the cell (16).

\section{Establishment and maintenance of the polarized epithelial cell}

The first step toward the establishment of a polarized epithelium is the organization of individual cells, through cell-cell and cell-substratum contacts, into a cohesive monolayer.

1. Abbreviations used in this paper: CAM, cell adhesion molecules; GPI, glycosylphosphatidylinositol; HA, hemagglutinin; MDCK, Madin-Darby canine kidney cells; TGN, trans-Golgi network; VSV, vesicular stomatitis virus.
Subsequently, cells develop biochemically and physiologically distinct apical and basolateral membrane domains, and cytoplasmic and cytoskeletal organization (2). In the mammalian embryo, formation of a polarized epithelium (trophectoderm) occurs at the 8 cell stage (morula) during induction of extensive cell-cell contact (compaction) (17). Cell-cell and cellsubstratum contact also induces development of cell polarity in freshly isolated hepatocytes and MDCK cells previously grown under suspension conditions. Before this cellular reorganization, surface membrane proteins and lipids are randomly distributed over the entire surface membrane (18). Polarization of the apical membrane follows either cell substratum attachment or cell-cell contact, but basolateral membrane polarization requires extensive cell-substratum and cell-cell contact (19).

Cell-cell contact and the establishment of polarity. Cellcell recognition and contact between individual cells is initiated by cell adhesion molecules (CAMs). CAMs are cell surface membrane glycoproteins that are highly conserved, bind to each other in a homophilic manner and mediate calciumdependent aggregation of epithelial cells (20-22). Cell-cell contact results in the rapid assembly of other components of the junctional complex (e.g., tight junctions and desmosomes) and the subsequent demarcation of apical and basolateral membrane domains. After cell-cell contact there is a redistribution of surface membrane and cytoskeletal proteins to the basolateral membrane. For example, after cell-cell and cellsubstratum contact, $\mathrm{Na}^{+}, \mathrm{K}^{+}$-ATPase, ankyrin, and fodrin, which are distributed randomly over the entire surface membrane, undergo a spatial reorganization resulting in the formation of metabolically stable, nonextractable cytoskeletalmembrane protein complexes localized to the basolateral membrane $(23,24)$.

This process of recruitment and stabilization of surface membrane proteins may be initiated by cytoskeletal-CAM interactions. As noted earlier, $\mathrm{Na}^{+}, \mathrm{K}^{+}$-ATPase forms a metabolically stable detergent-insoluble complex with actin, fodrin, and ankyrin (12, 13; Fig. 1, inset). Uvomorulin (E-cadherin) may also form complexes with ankyrin and fodrin (25). Interestingly, deletion of part of the cytoplasmic domain of uvomorulin inhibits cell-cell binding in transfected fibroblasts (26), perhaps because of loss of linkage to cytoplasmic proteins (25). It is, therefore, possible that uvomorulin-cytoskeletal interactions form a nucleation site for recruitment of other cytoskeletal-membrane protein complexes to the basolateral membrane (e.g., $\mathrm{Na}^{+}, \mathrm{K}^{+}$-ATPase).

Polarized targeting to distinct membrane domains. Further genesis and maintenance of the polarized organization of epithelial cells is dependent on the targeting of proteins and lipids to specific membrane domains. The observation that enveloped RNA viruses bud vectorially in MDCK cells permitted the dissection of intracellular targeting of individual enveloped glycoproteins to different plasma membrane domains (27). In polarized epithelial cells, influenza virus hemagglutinin (HA) is transported to the apical membrane, and the $G$ protein of vesicular stomatitis virus (VSV) is transported to the basolateral membrane (27). These studies demonstrated that both glycoproteins were cotransported through the endoplasmic reticulum and Golgi complex. However, in the trans-cisternae of the Golgi complex (TGN), the pathways of these proteins separated and $\mathrm{HA}$ and $\mathrm{G}$ proteins were transported via different vesicles to their target membrane domains (28) (Fig. 1). More 


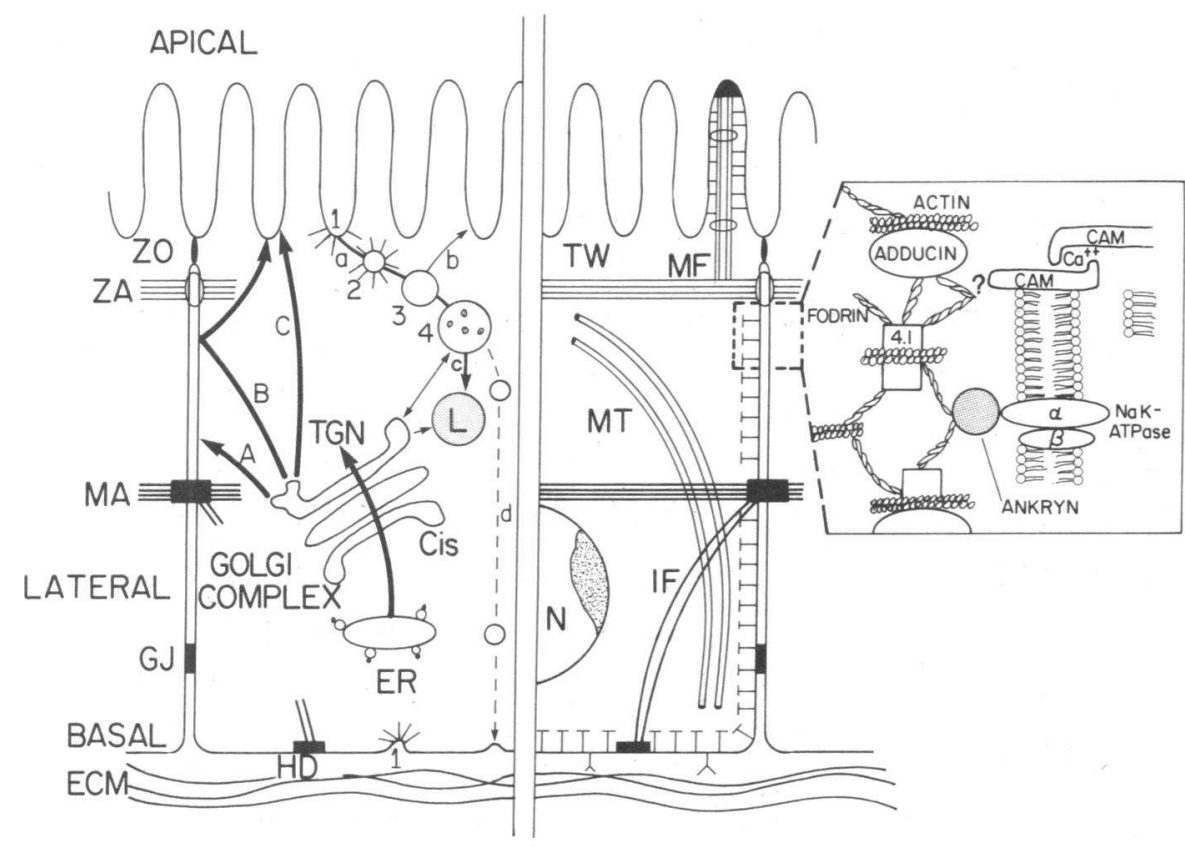

Figure 1. Cellular components and processes involved in the establishment and maintenance of epithelial cell polarity. On the left, apical and basolateral protein synthesis, sorting, and targeting pathways are shown. Basolateral membrane $(A)$ and apically $(C)$ destined protein vesicles move from the TGN to their respective surface membrane domains. In hepatocytes, apical proteins may first be delivered to the basolateral domain and then endocytosed and redistributed to the apical membrane $(B)$. Apical endocytosis is also shown. Receptor-mediated endocytosis starts $(a)$ with the formation of a clatherin-coated vesicle (2) from a clatherin-coated pit (I). Clatherin then disassembles leaving primary or early endosomes. From primary endosomes, membrane components can either recycle back to the surface membrane of origin $(b)$, be transferred $(c)$ to lysosomes $(L)$ via multivesicular bodies (4), or undergo transcytosis $(d)$. On the right, components of the cytoskeletal network are shown, including actin microfilaments

$(M F)$, which form the structural core within each microvillus and are held together by the "bundling" proteins villin and fimbrin $(0)$. Microtubules $(M T)$ form along the apico-basal axis of the cell and intermediate filaments $(I F)$ interconnect adjacent cells at macula adherens $(M A)$ and the substratum at hemi-desmosomes $(H D)$. Inset, The interactions of actin microfilaments and their associated cytoskeletal proteins. The junctional complex along the lateral membrane includes the zonula occludens $(Z O)$, zonula adherens $(Z A)$, maculae adherens $(M A)$, gap junctions $(G J)$, and CAMs.

recent studies of the targeting of endogenous apical and basolateral membrane proteins in MDCK cells have yielded similar conclusions. For example, $\mathrm{Na}^{+}, \mathrm{K}^{+}$-ATPase and other glycoproteins were targeted directly to the basolateral membrane (29) and apical membrane (30), respectively, in MDCK cells.

An additional intracellular pathway for the delivery of apical proteins has been recently described. Hubbard and coworkers showed that both apical and basolateral membrane proteins in hepatocytes were first transported from the TGN to the basolateral membrane (sinusoidal) surface (31). Thereafter, proteins destined for the apical domain were specifically retrieved from the membrane (endocytosis) and redistributed to the apical surface (Fig. 1). Similar results have been obtained in studies of protein targeting in the small intestine (32), although conflicting reports using a similar model, in the small intestine, have been reported by two different laboratories $(33$, 34). Clearly, a basolateral to apical membrane "tract" exists as hepatocytes, enterocytes, and transfected MDCK cells use this transport pathway for the transcytosis of polymeric Igs (35). Further studies, therefore, will be necessary to define the extent to which this pathway is involved in the targeting of specific membrane components to the apical surface.

Understanding the intracellular transport of lipids to the surface membrane (establishment phase) has been difficult because of the lack of immunologic techniques and domain-specific markers. Like proteins, phospholipids are synthesized in the endoplasmic reticulum, move to the cis-Golgi, and migrate to the TGN (3). However, the mechanisms involved in the transport of phospholipids from the TGN to the surface membrane remain in question. While it is generally felt that phospholipids travel in protein-shuttling, domain-specific vesicles (3), two new lines of evidence indicate that additional proteinindependent pathways may also be involved $(36,37)$.
The mechanisms involved in sorting and targeting proteins to different plasma membrane domains remain poorly understood. It has been proposed that within the Golgi complex specific receptors target proteins to their final destination. For example, mannose-6-phosphate receptors in the Golgi complex recognize phosphorylated mannose side chains on lysosomal hydrolases and then target these proteins to lysosomes (38). Sorting signals for the apically destined influenza virus HA protein and basolaterally targeted VSV G protein have been localized to the external domain of each protein (39). However, receptor proteins that recognize these signals have not yet been demonstrated. Recently it has been suggested that the targeting of apical membrane glycoproteins may be mediated through the covalent linkage to a glycolipid, glycosyl-

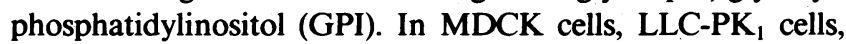
and two human intestinal cell lines, endogenous GPI-linked glycoproteins localized preferentially to the apical surface $(40,41)$.

The role of microtubules in the movement of surface membrane-destined vesicles has been demonstrated in several systems. While the polarized basolateral delivery of VSV G protein in MDCK cells (42), and $\mathrm{Na}^{+}, \mathrm{K}^{+}$-ATPase in intestinal epithelium (43) was unaffected by microtubule depolymerizing agents, the apical membrane delivery of endogenous membrane proteins in intestinal epithelial cells, and influenza HA in MDCK cells was dependent on the presence of intact microtubules $(42,43)$. Disruption of microtubules both in vitro and in vivo led to the accumulation of apical markers and microvilli-like structures in the basolateral membrane (43). This microtubule-directed transport of vesicles to the apical membrane may be mediated by two soluble cytoplasmic ATPases, kinesin and dynein (44).

Epithelial cells can also qualitatively and quantitatively 


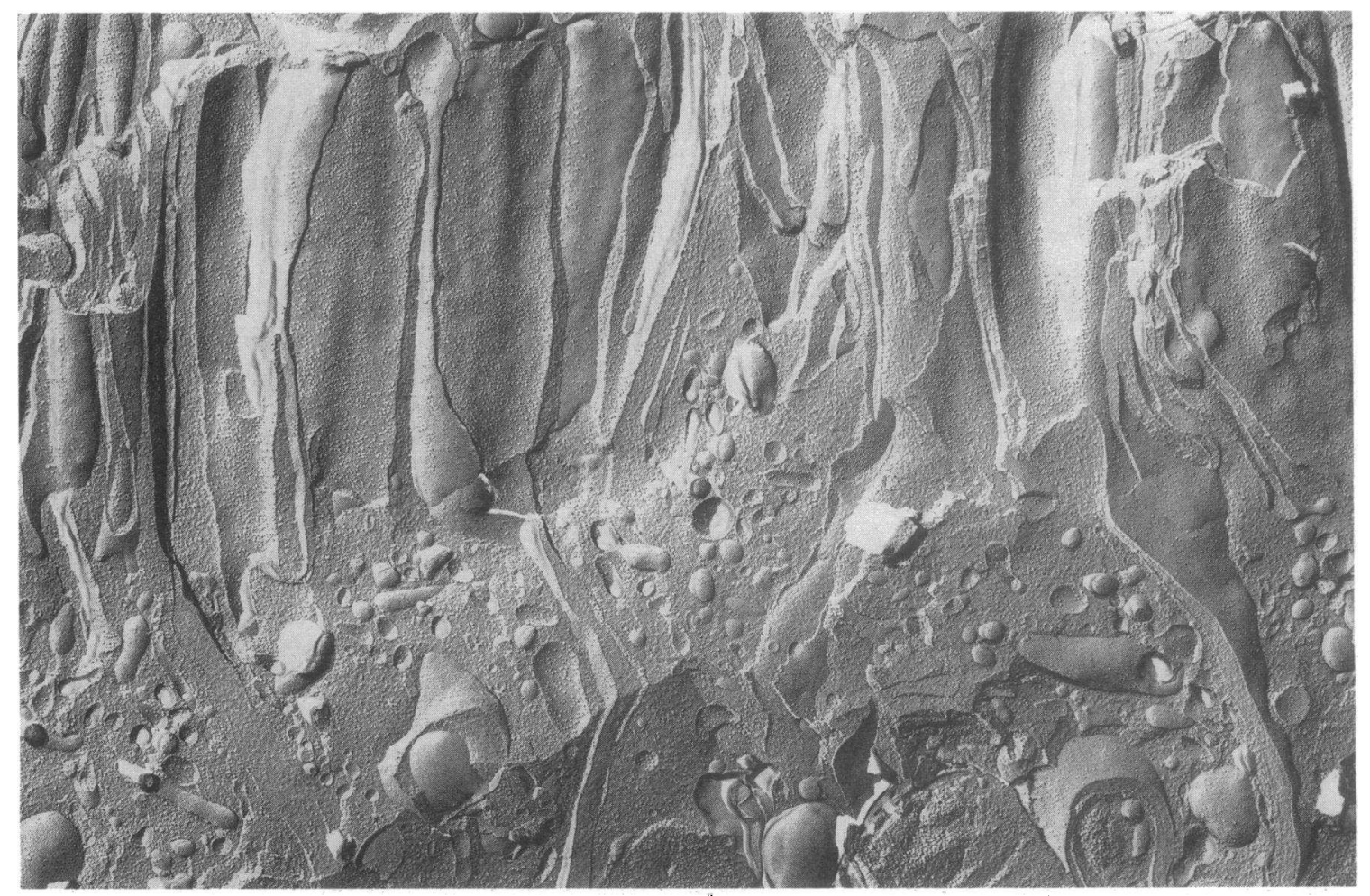

Figure 2. Freeze-fracture electron micrograph of the apical portion of rat renal proximal tubule cells after 50 min of ischemia. $\times 23,000$.

alter the protein composition of plasma membrane domains by endocytosis and exocytosis. This has been demonstrated in epithelial cells, such as the intercalated cells of the cortical collecting tubule, which amplify or diminish apical membrane $\mathrm{H}^{+}$-ATPases in response to changes in $\mathrm{PCO}_{2}$ and $\mathrm{pH}(45)$. These cells are also capable of reversing surface membrane polarity in response to environmental stimuli (46).

Epithelial cells that conduct both apical and basolateral endocytosis and transcytosis must limit the intracellular mixing of surface membrane proteins and lipids from different domains. A highly efficient sorting mechanism is essential if distinct apical and basolateral membrane domains are to be maintained, since the quantity of surface membrane internalized via endocytosis per hour can greatly exceed the entire membrane surface area (47). Sorting of endocytosed surface membrane occurs in the endosomal compartment (Fig. 1) where three subsequent processing pathways are available: recycling to the original surface membrane $(b)$; delivery to lysosomes $(c)$; and delivery to the alternate membrane domain (transcytosis; $d$ ) (for review, see reference 47). Recycling of membrane components to the original membrane is an efficient process (48); however, the mechanisms responsible for intracellular sorting of endocytic vesicles remain largely unknown.

Cytoskeleton and tight junctions in the maintenance of polarity. Once membrane proteins and lipids have been delivered and incorporated into specific membrane domains, it is essential that their polarized distribution be maintained. Two cellular mechanisms are thought to be involved: the tight junction and the actin-associated cytoskeleton. The actin-associated cytoskeleton (Fig. 1, inset) may function to reduce the lateral mobility of specific membrane proteins and hence maintain the segregation of these proteins. This cytoskeletal tethering mechanism has been studied in erythrocytes where the cytoskeletal matrix is bound to Band III (49) by ankryn and spectrin. Using fluorescence recovery after photobleaching, the diffusion coefficient of Band III increased 50 -fold in spectrindeficient spherocytes or under conditions favoring spectrin dissociation (50). Salas et al. (51), using fluorescence recovery after photobleaching and Triton X-100 extractability techniques in MDCK cells, demonstrated that both apical and basolateral membrane domains contain mobile and immobile membrane protein fractions. The immobile membrane proteins were not extracted with Triton X-100, indicating that they were linked to the cytoskeleton. Significantly, when cytoskeletal associated membrane proteins were localized to the alternate (incorrect) surface membrane domain, the proteins were mobile and extractable (51). This suggests the presence of domain-specific cytoskeletal matrices that bind to and stabilize specific membrane proteins.

Since some basolateral and apical domain-specific proteins demonstrate free rotational diffusion and no cytoskeletal associations (under the above criteria), other mechanism(s) must operate to maintain their high degree of polarity. It has been proposed that the tight junction may form a diffusion barrier (fence) in the membrane and thus limit diffusion between membrane domains. This hypothesis is supported for proteins by several lines of indirect evidence (for review, see references 13 and 14). Direct evidence, however, indicates that surface membrane lipid polarity requires intact tight junctions. When a fluorescent phosphatidylethanolamine derivative was introduced into the external leaflet of the apical membrane of MDCK cells, the probe remained localized within the apical domain unless cell-cell contacts were disrupted (52). 


\section{Altered epithelial cell polarity in pathologic states}

The establishment and maintenance of polarity in epithelial cells is a complex multistage process. It is probable, therefore, that alterations in one or more of these cellular processes play a role in the etiology of specific disease states. If this is the case, then pathologic processes in epithelial cells could be classified according to an abnormality in one or more of these processes. Here we will examine four disease states in that context.

Microvillus inclusion disease (Davidson's disease) is an autosomal recessive disorder characterized clinically by protracted diarrhea and high mortality (53). Morphologically, the proximal enterocytes and colonic cells have scanty, disorganized, short microvilli, and numerous cytoplasmic vesicular bodies that consist of a complete apical membrane with microvilli and an associated terminal web (54). Because of these alterations, "mature" enterocytes are unable to absorb ions, nutrients, and water. Adjacent Goblet, Paneth, and enteroendocrine cells appear normal (54). The mechanism(s) that results in the formation of these abnormal vesicular bodies and apical surface membranes is unknown. However, recent in vitro cell culture studies have demonstrated the existence of similar vesicular bodies in MDCK epithelial cells grown at low densities in the absence of cell-cell contact (55). These intracellular vesicular structures, termed vacuolar apical compartments, possess microvilli and apical marker proteins but exclude basolateral membrane proteins (55). Treatment of intestinal cells with microtubule depolymerizing drugs also leads to the occurrence of similar structures, which were localized to the basolateral membrane (43). After removal of the colchicine, these aberrant structures were shuttled to their correct apical domain, presumably via a microtubule-dependent process. Taken together, these data suggest that a defect in microtubule-mediated delivery of apically destined vesicles may be playing a role in the etiology of Davidson's disease. Other potential mechanisms, however, include the inability of apically destined vesicles to fuse with the apical surface, or inefficient recycling of endocytic membrane components.

Carcinogenesis is a complex multistage process characterized by loss of growth regulation, invasiveness, angiogenesis, and metastasis. $80-90 \%$ of human tumors are of epithelial origin (carcinomas). Many carcinomas are characterized by alterations in surface membrane morphology, cell polarity, gap junctions, tight junctions, and cell-cell adhesiveness (56, 57). Furthermore, tumor invasiveness is inversely related to cellular differentiation (58).

Recent cell culture evidence indicates that the invasive aspect of this process may be related to loss of cell-cell adhesion. First, transformation of MDCK cells with either Moloney or Harvey sarcoma viruses resulted in the formation of invasive cells with fibroblastic morphology that lacked surface membrane expression of the cell adhesion protein, uvomorulin. On the other hand, transformed cells that maintained epithelial characteristics and a high surface membrane uvomorulin content were noninvasive (59). Reductions in cell-cell contacts had been previously reported when pp60 v-src was expressed in MDCK cells (60), and when SV-40-DNA and ras-DNA were used to transform primary rabbit mammary epithelial cells (61).

Second, treatment of confluent monolayers of MDCK cells with an anti-uvomorulin MAb resulted in dissociation of cells, loss of surface expression of uvomorulin, and development of a fibroblastic phenotype. Concurrently, these cells became in- vasive in collagen gels and embryonal heart tissue (59). Together these data suggest that epithelial cell invasiveness, and therefore carcinogenesis, may in part be related to loss of cellcell adhesion and surface membrane polarity. The cellular event(s) resulting in diminished expression of uvomorulin and the mechanism(s) leading to cellular invasiveness remain unknown.

Ischemia in proximal tubule cells and bile duct ligation (hepatocytes) both result in loss of apical microvilli with cellular internalization and blebbing of the apical membrane into the lumen, loss of surface membrane polarity of both apical and basolateral membrane domain-specific markers (62-64), alterations in apical terminal web actin microfilaments $(65,66)$, and reduction in vectorial transport functions $(63,67,68)$. The alterations in vectorial transport functions were related to the redistribution of surface membrane phospholipids (67) and domain-specific apical and basolateral membrane enzymes $(63,68)$. For example, ischemia-induced redistribution of $\mathrm{Na}^{+}, \mathrm{K}^{+}$-ATPase to the apical membrane, in renal proximal tubule cells, was associated with reduced $\mathrm{Na}^{+}$reabsorption, probably secondary to $\mathrm{Na}^{+}, \mathrm{K}^{+}$-ATPase pumping $\mathrm{Na}^{+}$back into the urinary lumen (68). Furthermore, reestablishment of surface membrane $\mathrm{Na}^{+}, \mathrm{K}^{+}$-ATPase polarity was essential for restoration of normal cellular $\mathrm{Na}^{+}$transport (69).

The cellular events occurring during cell injury remain largely unknown. However, ischemia in renal proximal tubule cells results in the rapid duration-dependent opening of tight junctions, which precedes or occurs concurrently with the redistribution of surface membrane phospholipids and $\mathrm{Na}^{+}, \mathrm{K}^{+}$ATPase to the alternate surface membrane domain (70). Microfilament disruption may also be involved in ischemic cell injury, as disruption of terminal web and microvillar actin microfilaments occurs early and in a time-dependent fashion (65). Disruption of microvillar core microfilaments may be responsible for loss of apical membrane and the markedly altered morphology of apical microvilli seen after ischemic injury (Fig. 2). Microfilament disruption during ischemia may be the result of cellular ATP depletion as metabolic inhibitors result in breakdown of actin microfilaments in cell culture studies (71). Taken together, these data indicate that the cell's inability to maintain surface membrane polarity may correlate with the disruption of lateral cell-cell attachments and the actin cytoskeleton. Under these aberrant conditions, apical and basolateral membrane proteins and lipids may be capable of lateral diffusion, within the plane of the membrane bilayer, into the alternate domain, resulting in the loss of surface membrane polarity. For repolarization of surface membrane lipids and proteins, and therefore the restoration of normal cellular function, cell-cell contacts and cytoskeletal organization must be reestablished, and the abnormal membrane components must be removed.

In summary, the establishment and maintenance of epithelial polarity is essential for normal cell structure and function. Many pathologic processes may be secondary to either fundamental errors in the complex processes involved in the establishment and maintenance of epithelial polarity, or loss of the cell's ability to maintain the polar state secondary to stresses placed on the cell. Continued detailed analysis of these pathologic states and of the mechanisms that are involved in the establishment and maintenance of polarity in epithelial cells may further our understanding of the etiology of specific disease processes. 


\section{Acknowledgments}

The authors thank Rolf H. Dahl and the laboratory of Dr. L. Andrew Staehelin for assistance with the freeze fracture electron micrograph (cover photo).

This work was supported by grants to Dr. Molitoris from the National Institutes of Health (NIH) DK-41126 and the Veterans Administration Research Service; grants to Dr. Nelson from the National Science Foundation (DCB-8609091) and the NIH (GM-35527); grants to the Institute for Cancer Research from the NIH (CA-06927 and RR-05539); and an appropriation from the Commonwealth of Pennsylvania. Dr. Molitoris is a recipient of a Clinical Investigator Award from the Veterans Administration Research Service. Dr. Nelson is a recipient of an Established Investigator Award from the American Heart Association.

\section{References}

1. Simons, K., and S. D. Fuller. 1985. Cell surface polarity in epithelia. Annu. Rev. Cell Biol. 1:243-288.

2. Rodriguez-Boulan, E., and W. J. Nelson. 1989. Morphogenesis of the polarized epithelial cell phenotype. Science (Wash. DC). 245:718-725.

3. Van Meer, G., and K. Simons. 1988. Lipid polarity and sorting in epithelial cells. J. Cell. Biochem. 36:51-58.

4. Molitoris, B. A., and C. Hoilien. 1987. Static and dynamic components of renal corticol brush border and basolateral membrane fluidity: role of cholesterol. J. Membr. Biol. 99:165-172.

5. Madara, J. L. 1989. Loosening tight junctions. Lessons from the intestine. J. Clin. Invest. 83:1089-1094.

6. Gumbiner, B. 1988. The structure, biochemistry, and assembly of epithelial tight junctions. Am. J. Physiol. 253:C749-C758.

7. Parry, G., B. Cullen, C. S. Kaetzel, R. Kramer, and L. Moss. 1987. Regulation of differentiation and polarized secretion in mammary epithelial cells maintained in culture. Extracellular matrix and membrane polarity influences. J. Cell Biol. 105:2043-2051.

8. Klein, G., M. Langegger, R. Timpl, and P. Ekblom. 1988. Role of laminin A chain in the development of epithelial cell polarity. Cell. 55:331-341.

9. Bennett, V. 1989. The spectrin-actin junction of erythrocyte membrane skeletons. Biochim. Biophys. Acta. 988:107-121.

10. Mooseker, M. S. 1985. Organization, chemistry, and assembly of the cytoskeletal apparatus of the intestinal brush border. Annu. Rev. Cell Biol. 1:209-241.

11. Bershadsky, A. D., and J. M. Vasilier. 1988. Cytoskeleton. Plenum Publishing Corp., New York. 13-154.

12. Nelson, W. J., and P. J. Veshnock. 1987. Ankyrin binding to $\mathrm{Na}^{+}, \mathrm{K}^{+}$-ATPase and implications for the organization of membrane domains in polarized cells. Nature (Lond.). 328:533-536.

13. Nelson, W. J., and R. W. Hammerton. 1989. A membranecytoskeletal complex containing $\mathrm{Na}^{+}, \mathrm{K}^{+}-\mathrm{ATPase}$, ankyrin, and fodrin in Madin-Darby canine kidney (MDCK) cells. Implications for the biogenesis of epithelial cell polarity. J. Cell Biol. 108:893-902.

14. Allan, V. J., and T. E. Kreis. 1986. A microtubule-binding protein associated with membranes of the Golgi apparatus. J. Cell Biol. 103:2229-2239.

15. Matteoni, R., and T. E. Kreis. 1987. Translocation and clustering of endosomes and lysosomes depends on microtubules. J. Cell Biol. 105:1253-1265.

16. Warn, R. M., L. Flegg, and A. Warn. 1987. An investigation of microtubule organization and functions in living Drosophila embryos by injection of a fluorescently labeled antibody against tyrosinated $\alpha$ tubulin. J. Cell Biol. 105:1721-1730.

17. Fleming, T. P., and M. H. Johnson. 1988. From egg to epithelium. Annu. Rev. Cell Biol. 4:459-485.

18. Rabito, C. A., J. I. Kreisberg, and D. Wright. 1984. Alkaline phosphatase and glutamyl transpeptidase as polarization markers during the organization of LLC-PK 1 cells into an epithelial membrane. $J$. Biol. Chem. 259:574-582.

19. Vega-Salas, D. E., P. J. I. Salas, D. Gundersen, and E. Rodriguez-Boulan. 1987. Formation of the apical pole of epithelial (MadinDarby canine kidney) cells. Polarity of an apical protein is independent of tight junctions while segregation of a basolateral marker requires cell-cell interactions. J. Cell Biol. 104:905-916.

20. Edelman, G. M. 1986. Cell adhesion molecules in the regulation of anewal form and tissue pattern. Annu. Rev. Cell Biol. 2:81-116.

21. Nose, A., A. Nagafuchi, and M. Takeichi. 1988. Expressed recombinant cadherins mediate cell sorting in model systems. Cell. 54:993-1001.

22. Gumbiner, B., B. Stevenson, and A. Grimaldi. 1988. The role of the cell adhesion molecule uvomorulin in the formation and maintenance of the epithelial junctional complex. J. Cell Biol. 107:15751587.

23. Nelson, W. J., and P. J. Veshnock. 1986. Dynamics of membrane-skeleton (fodrin) organization during development of polarity in Madin-Darby canine kidney epithelial cells. J. Cell Biol. 103:17511765.

24. Nelson, W. J., and P. J. Veshnock. 1987. Modulation of fodrin (membrane skeleton) stability by cell-cell contact in Madin-Darby canine kidney epithelial cells. J. Cell Biol. 104:1527-1537.

25. Nelson, W. J., E. M. Shore, A. Z. Wang, and R. W. Hammerton. 1990. Identification of a membrane-cytoskeletal complex containing the cell adhesion molecule uvomorulin (E-cadherin), ankyrin, and fodrin in Madin-Darby canine kidney (MDCK) epithelial cells. $J$. Cell Biol. In press.

26. Nagafuchi, A., and M. Takeichi. 1988. Cell binding function of E-cadherin is regulated by the cytoplasmic domain. EMBO (Eur. Mol. Biochem. Organ.) J. 7:3679-3684.

27. Rodriguez-Boulan, E. J., and D. D. Sabatini. 1978. Asymmetric budding of viruses in epithelial monolayers: a model system for the study of epithelial cell polarity. Proc. Natl. Acad. Sci. USA. 75:50715075.

28. Rindler, M. J., I. E. Ivanov, H. Plesken, and D. D. Sabatini. 1985. Polarized delivery of viral glycoproteins to the apical and basolateral membranes of MDCK cells infected with temperature sensitive viruses. J. Cell Biol. 100:136-151.

29. Caplan, M. J., H. C. Anderson, G. E. Palade, and J. D. Jamieson. 1986. Intracellular sorting and polarized cell surface delivery of $\mathrm{Na}^{+}, \mathrm{K}^{+}$-ATPase, an endogenous component of MDCK cell basolateral plasma membranes. Cell. 46:623-631.

30. Lisanti, M. P., A. Le Bivic, M. Sargiacomo, and E. RodriguezBoulan. 1989. Steady-state distribution and biogenesis of endogenous Madin-Darby canine kidney glycoproteins. Evidence for intracellular sorting and polarized cell surface delivery. J. Cell Biol. 109:2117-2127.

31. Bartles, J. R., H. M. Feracci, B. Stieger, and A. L. Hubbard. 1987. Biogenesis of the rat hepatocyte plasma membrane in vivo. Comparison of the pathways taken by apical and basolateral proteins using subcellular fractionation. J. Cell Biol. 105:1241-1252.

32. Massey, D., H. Feracci, J. P. Gorvel, A. Rigal, J. M. Soulié, and S. Maroux. 1987. Evidence for the transit of aminopeptidase $N$ through the basolateral membrane before it reaches the brush border of enterocytes. J. Membr. Biol. 96:19-25.

33. Danielsen, E. M., and G. M. Cowell. 1985. Biosynthesis of intestinal microvillar proteins: evidence for an intracellular sorting taking place in, or shortly after, exit from the golgi complex. Eur. J. Biochem. 152:493-499.

34. Ahnen, D. J., N. A. Santiago, D. J. P. Cezard, and G. M. Gray. 1982. Intestinal amino-oligopeptidase: in vivo synthesis on intracellular membranes of rat jejunum. J. Biol. Chem. 257:12129-12135.

35. Breitfeld, P. P., J. M. Harris, and K. E. Mostov. 1989. Postendocytic sorting of the ligand for the polymeric immunoglobulin receptor in Madin-Darby canine kidney cells. J. Cell Biol. 109:475-486.

36. Koval, M., and R. E. Lagaro. 1989. Lipid recycling between the plasma membrane and intracellular compartments. Transport and 
metabolism of fluorescent sphingomyelin analogues in cultured fibroblasts. J. Cell Biol. 108:2160-2181.

37. Nichols, J. W. 1987. Binding of fluorescent-labeled phosphatidylcholine to rat liver non-specific lipid transfer protein. J. Biol. Chem. 262:14172-14177.

38. Griffiths, G., B. Hoflack, K. Simons, I. Mellman, and S. Kornfeld. The mannose-6-phosphate receptor and the biogenesis of lysosomes. Cell. 52:329-341.

39. Roth, M. G., D. Gundersen, N. Patil, and E. Rodriguez-Boulan. 1987. The large external demain is sufficient for the correct sorting of secreted or chimeric influenza virus hemagglutinins in polarized monkey kidney cells. J. Cell Biol. 104:769-782.

40. Lisanti, M. P., M. Sargiacomo, L. Graeve, A. Saltiel, and E. Rodriguez-Boulan. 1988. Polarized apical distribution of glycosylphosphatidylinositol-anchored proteins in a renal epithelial cell line. Proc. Natl. Acad. Sci. USA. 85:9557-9561.

41. Low, M. G., and A. R. Saltiel. 1988. Structural and functional roles of glycosyl-phosphatidylinositol in membranes. Science (Wash. DC). 239:268-275.

42. Rindler, M. J., I. E. Ivanov, and D. D. Sabatini. 1987. Microtubule-acting drugs lead to the nonpolarized delivery of the influenza hemagglutinin to the cell surface of polarized Madin-Darby canine kidney cells. J. Cell Biol. 104:231-241.

43. Achler, C., D. Filmer, C. Merte, and D. Drenkahahn. 1989. Role of microtubules in polarized delivery of apical membrane proteins to the brush border of the intestinal epithelium. J. Cell Biol. 109:179-189.

44. McIntosh, J. R., and M. E. Porter. 1989. Enzymes for microtubule-dependent motility. J. Biol. Chem. 264:1-5.

45. Al-Awqati, Q. 1986. Proton-translocating ATPases. Annu. Rev. Cell Biol. 2:179-199.

46. Satlin, L. M., and G. J. Schwartz. 1989. Cellular remodeling of $\mathrm{HCO}_{3}^{-}$-secreting cells in rabbit renal collecting duct in response to an acidic environment. J. Cell Biol. 109:1279-1288.

47. Gruenberg, J., and K. E. Howell. 1989. Membrane traffic in endocytosis: insights from cell-free assays. Annu. Rev. Cell Biol. 5:453-481.

48. Fuller, S. D., and K. Simons. 1986. Transferrin receptor polarity and recycling accuracy in tight and leaky strains of Madin-Darby canine kidney cells. J. Cell Biol. 103:1767-1779.

49. Tsuji, A., and S. Ohnishi. 1986. Restriction of the lateral motion of band 3 in the erythrocyte membrane by the cytoskeletal network: dependence on spectrin association state. Biochemistry. 25:6133-6139.

50. Sheetz, M. P., M. Schindler, and D. E. Koppel. 1980. Lateral mobility of integral membrane proteins is increased in spherocytic erythrocytes. Nature (Lond.). 285:510-511.

51. Salas, P. J. I., D. E. Vega-Salas, J. Hochman, E. RodriguezBoulan, and M. Edidin. 1988. Selective anchoring in the specific plasma membrane domain. A role in epithelial cell polarity. J. Cell Biol. 107:2363-2376.

52. Van Meer, G., and K. Simons. 1986. The function of the tight junction in maintaining differences in lipid composition between the apical and basolateral cell surface membrane domains of MDCK cells. EMBO (Eur. Mol. Biol. Organ.) J. 5:1455-1464.

53. Davidson, G. P., E. Cutz, J. R. Hamilton, and D. G. Gall. 1978 Familial enteropathy: a syndrome of protracted diarrhea from birth, failure to thrive, and hypoplastic villus atrophy. Gastroenterology. 75:783-790.

54. Cutz, E., J. M. Rhoads, B. Drumm, P. M. Sherman, P. R.
Durie, and G. G. Forstner. 1989. Microvillus inclusion disease: an inherited defect of brush border assembly and differentiation. N. Engl. J. Med. 320:646-651.

55. Vega-Salas, E. E., P. J. I. Salas, and E. Rodriguez-Boulan. 1988. Exocytosis of vacuolar apical compartment (VAC). A cell-cell contact controlled mechanism for the establishment of the apical plasma membrane domain in epithelial cells. J. Cell Biol. 107:1717-1728.

56. Weinstein, R. S., F. B. Merk, and J. Alroy. 1976. The structure and function of intercellular junctions in cancer. Adv. Cancer Res. 23:23-89.

57. Ahnen, D. J., P. K. Nakane, and W. R. Brown. 1982. Ultrastructural localization of carcinoembryonic antigen in normal intestine and colon cancer. Cancer (Phila.). 49:2077-2090.

58. Gabbert, H. 1985. Mechanism of tumor invasion: evidence from in vivo observations. Cancer Metastasis Rev. 4:293-309.

59. Behrens, J., M. M. Mareel, F. M. Van Roy, and W. Birchmeier. 1989. Dissecting tumor cell invasion. Epithelial cells acquire invasive properties after the loss of uvomorulin-mediated cell-cell activation. $J$. Cell Biol. 108:2435-2447.

60. Warren, S. L., and W. J. Nelson. 1987. Non-mitogenic morpho-regulatory action of pp6D V-SRC on multi-cellular epithelial structures. Mol. Cell. Biol. 7:1326-1337.

61. Garcia, I., B. Sordat, E. Rauccio-Farinon, M. Dunand, J. P. Kraehenbiihl, and H. Diggelmann. 1986. Establishment of two rabbit mammary epithelial cell lines with distinct oncogenic potential and differentiated phenotype after micro-injection of transforming genes. Mol. Cell. Biol. 6:1974-1982.

62. Molitoris, B. A., C. A. Hoilien, R. H. Dahl, D. J. Ahnen, P. D. Wilson, and J. Kim. 1988. Characterization of ischemia-induced loss of epithelial polarity. J. Membr. Biol. 106:233-242.

63. Fricker, G., L. Landmann, and P. J. Meier. 1989. Extra-hepatic obstructive cholestasis reverses in the bile salt secretory polarity of rat hepatocytes. J. Clin. Invest. 84:876-885.

64. Durand-Schneider, A. M., M. Maurice, M. Dumont, and G. Feldman. 1987. Effect of colchicine and phalloidin on the distribution of three plasma membrane antigens in rat hepatocytes: comparison with bile duct ligation. Hepatology (Baltimore). 7:1239-1248.

65. Kellerman, P. S., R. A. F. Clark, C. A. Hoilien, S. L. Linas, and B. A. Molitoris. The role of microfilament disruption in ischemia-induced acute renal failure. Submitted for publication.

66. Phillips, M. J., S. Poucell, and M. Oda. 1986. Biology of disease: mechanism of cholestasis. Lab. Invest. 54:593-608.

67. Molitoris, B. A., and R. Kinne. 1987. Ischemia induces surface membrane dysfunction. Mechanism of altered $\mathrm{Na}^{+}$-dependent glucose transport. J. Clin. Invest. 80:647-654.

68. Molitoris, B. A., L. K. Chan, J. I. Shapiro, J. D. Conger, and S. A. Falk. 1989. Loss of epithelial polarity: A novel hypothesis for reduced proximal tubule $\mathrm{Na}^{+}$transport following ischemic injury. $J$. Membr. Biol. 107:119-127.

69. Spiegel, D. M., P. D. Wilson, and B. A. Molitoris. 1989. Epithelial polarity following ischemia: a requirement for normal cell function. Am. J. Physiol. (Renal Fluid Electrolyte Physiol.). 256:F430F436.

70. Molitoris, B. A., R. H. Dahl, and S. A. Falk. 1989. Ischemiainduced loss of epithelial polarity. Role of the tight junction. J. Clin. Invest. 84:1334-1339.

71. Bershadsky, A. D., V. I. Gelfand, T. M. Svitkina, and I. S. Tint. 1980. Destruction of microfilament bundles in mouse embryo fibroblasts treated with inhibitors of energy metabolism. Exp. Cell Res. 127:421-429. 